\title{
SIMULATION ANALYSIS OF AUTOMATED EARTH BORING METHODS
}

\author{
Daniel W. Halpin, Professor and Head \\ Antonio A. González-Quevedo, Ph.D. Candidate \\ Division of Construction Engineering and Management \\ Civil Engineering Building, Purdue University \\ West Lafayette, Indiana 47906 , USA \\ Simaan AbouRizk, Assistant Professor \\ Department of Civil Engineering \\ University of Alberta, Edmonton, Alberta, Canada T6G-2G7
}

\section{SUMMARY}

Simulation offers a tool that enables the simulator to compare alternative technologies in an environment that closely models the real world. Advantages of automation from a production perspective can be established by building a simulation model and experimenting with it on a computer. This paper illustrates this by specifically simulating a liner plate tunneling system using MicroCYCLONE, an easy-to-use simulation methodology. To compare the results we perform the same simulation experiments using SLAM II, a general purpose simulation language. Both simulation systems yield the same results. The advantages of CYCLONE mainly lie in its simplicity and ease of use.

\section{INTRODUCTION}

Introduction of new technologies to the construction industry has been slow compared to other industries. A variety of factors contribute to this slow transfer including the traditional craft oriented structure of the construction industry. The risk involved in applying new methods or technologies plays a significant role in stagnating the transfer of new technologies to construction. This stems mainly from the inability of contractors and/or owners to easily quantify these risks.

A number of mathematical and analytical tools are available to assist in risk assessment in construction. This paper is concerned with introducing a simulation-based method for modeling and evaluating technologies when production rates, time required to complete a project, and cost are the basic factors to investigate. To illustrate how this can be done, a trencheless excavation operation is considered. The simulation is carried by CYCLONE. This simulation method was mainly chosen because of its simplicity and ease of learning and use. The results were also validated using a general purpose simulation language namely SLAM II.

open trenching excavation is becoming unacceptable especially in the cities, because of the disruptions it causes to the general public and the businesses. New methods of excavating, known generically as Trenchless Excavation Construction (TEC), have been gaining in popularity because they provide a means of installing needed utilities without causing undue disruptions to the population.

The methods currently available can be classified into three major categories: (1) horizontal earth boring, (2) pipe jacking, and (3) utility tunneling (Iseley 1988) as illustrated in Figure 1 prepared by Iseley (1988). 
Computer simulation presents a good tool to quantify the attainable levels of production while incorporating the type of technology employed, site conditions, random effects (such as weather and equipment breakdown) in the simulation model. These results can be used to decide whether using the trenchless excavation method can achieve the same production levels as the classical techniques and at what cost. Other effects such as discuption of the environment and initial capital investment in the new technology are often subjectively evaluated. Thomson (1987), for example, presents the cases where TEC methods are most commonly used and discusses the factors that should be considered in the selection of the appropriate method.

The major obstacle involved in the use of simulation in analyzing these problems is the difficulty associated with learning and employing a general purpose simulation concept. The CYCLONE method (Halpin 1976) presents a significant resolution of this problem. The method is simple to learn, versatile in its applications (particularly in construction) and produces standard reports that include most data sought in a construction simulation experiment.

\section{OUTLINE OF WORK}

The paper is organized as follows: utility tunneling and the tunnel lining plates (TLP) methods will be reviewed with their major advantages in section 3. The CYCLONE simulation models and the companion SLAM II process-interaction models of the TLP method are presented in section 4. The fifth section presents an analysis of the simulation results and compares the process duration from both systems. Section 6 summarizes the uses of simulation in decision making based on CYCLONE models and a study conducted by Schmitt (1990). Finally section 7 presents general conclusions.

\section{UTILITY TUNNELS: TUNNEL LINING PLATES}

In utility tunneling, workers dig a tunnel and place tunnel liner plates. These liner plates act as support until the utility is installed and a filler material is placed between the utility and the liner plates. The minimum diameter of the liner plates should be 4 feet $(1.22$ meters) for the operation to be practical. There is no maximum theoretical limit for the liner plates' diameter, nor for the length of the bore. (Iseley 1988)

A typical liner plate installation is composed of a number of activities that are described in Table $I$. The stochastic duration parameters for each activity are also included in Table I. All stochastic durations are represented by triangular distributions. Triangular distributions require a minimum duration, the modal duration, and a maximum duration. These estimates are often readily available from a person knowledgeable about the process.

The logic and sequence of activities of the TLP method are shown in Table I. It should be noted that the sequence represented by activities 6 through 10 is repeated until the desired tunnel length is achieved. The length of each liner plate is 16 inches $(406 \mathrm{~mm})$, and since 40 linear feet (12.2 meters) of liner will be placed, then activities 6 through 10 must be repeated 30 times. These durations are representative of a tunneling operation in clay. The advantages of the TLP system (Iseley 1988) include properties such as: (1) tunnel entrance can be of minimum size, thus 
Table I. Description of Activities of Liner Plate Tunneling Operation with stochastic Durations

Soil Condition: Clay

Liner Plate Diameter:

48 inches

\begin{tabular}{||l||l|l|l|l||}
\hline No. & Description & L & M & U \\
\hline 1 & Assemble entrance pit rings & 60 & 75 & 90 \\
\hline 2 & Set rings in pit & 30 & 45 & 60 \\
\hline 3 & Pour concrete around rings & 60 & 75 & 90 \\
\hline 4 & Pour concrete floor & 50 & 60 & 70 \\
\hline 5 & Align grade & 20 & 30 & 40 \\
\hline 6 & Excavate 16 inches & 12 & 15 & 20 \\
\hline 7 & Haul muck & 5 & 8 & 12 \\
\hline 8 & Advance tunnel shield & 1 & 2 & 3 \\
\hline 9 & Retract rams & 1 & 2 & 3 \\
\hline 10 & Install one ring 16 inches & 20 & 22 & 25 \\
\hline
\end{tabular}

reducing the time required for bore pit construction; (2) more versatility with regard to changed ground conditions than mechanical excavation methods because corrective action can be taken quickly; (3) highly accurate because workers are closely checking the line and grade since it is basically a manual process, the possibility of a mechanical breakdown is nonexistent. The disadvantages include that TEC is not suitable or feasible for accommodating small diameter pipes, its production rates are lower, and it is less effective for larger bore lengths and diameters.

\section{SIMULATION MODELS}

The liner plate tunneling operation is simulated using two simulation languages, CYCLONE and SLAM II. A very short description of these two languages will be presented herein. For a more detailed description of CYCLONE and SLAM II refer to the references provided (Halpin 1990 and Pritsker 1986).

MicrOCYCLONE (Lluch and Halpin 1982) is a microcomputer based simulation program designed for modeling and analyzing site level processes using the CYCLONE methodology. Activities with their related durations, activities competing for resources, identification of resources, and the resource unit flow through the network work tasks are the basic elements for the modeling of construction operations. CYCLONE uses four basic graphical elements to compose the network to be simulated. These basic modeling elements are shown in Figure 2. CYCLONE can be used to simulate construction processes which are dynamic and stochastic in nature. Incorporating random factors in a model automated sensitivity analysis and automated analysis of random simulation output are supported by the system. (Halpin 1990) 
Process-interaction simulation consists of a model in which units of traffic (customers, transactions, units) flow through a queuing network, contending for service at the nodes of the network. The network portion of SLAM II processes arrivals at each node and provides standard support functions like sampling random variates, collecting statistics, and controlling the model run. The basic network elements in SLAM II are transactions, activities, resources, and nodes. The transactions represent units of traffic flowing through the network. The activities represent the time delays in the movement of the transactions. The resources are finite capacity system facilities that can be allocated and removed in any integer amounts. Their use is not tied up to the traversal of a single branch in the network. (Pritsker 1986)

\subsection{CYCLONE MODEL}

The CYCLONE model developed by schmitt (1990) is shown in Figure 3. Activities 1 through 5 are performed sequentially. Then activities 6 through 9 (excavation cycle) can be performed sequentially. The two resources in QUEUE 54 insure that the installation of the liner plate (activity 10) can proceed at the same time the excavation cycle is proceeding. Activities 6 through 9 will be performed 30 times in order to simulate the placement of 40 linear feet $(12.2 \mathrm{~m})$ of liner.

\subsection{SLAM II PROCESS-INTERACTION MODEL}

The SLAM II process-interaction model is shown in Figure 4. Some highlights of the model are as follows. The entity traversing the network is a 16 inch $(406 \mathrm{~mm})$ liner plate. Two resources are required for this operation, namely a crew and a pit. The variable $\mathrm{XX}(1)$ is used as a counter. This counter and logical statements associated with it, causes activities 6 through 10 to be repeated 30 times to achieve the placement of 40 linear feet $(12.2 \mathrm{~m})$ of liner. Activities 6 through 9 are performed sequentially. Activities 6 (excavate) and 10 (place liner) can commence as soon as activity 9 is completed.

\section{PROJECT DURATION OBTAINED FROM SIMULATIONS}

Two sets of simulation experiments were performed. The first experiment uses deterministic durations for all activities in both the CYCLONE and SLAM II models to enable proper comparison of the results. The second simulation experiment uses triangularly distributed activity duration to enable proper depiction of the real situation. Forty simulation runs were made to provide enough data to categorize the distribution of the simulation output. The $(100-\alpha) \%$ confidence interval for the mean process duration was computed as follows:

$$
D_{\text {avg }} \pm t_{[1-\alpha / 2, v]}\left(s / n^{\frac{1}{2}}\right)
$$

where:

$$
\begin{aligned}
& \mathrm{D}_{\text {avg }}=\text { mean duration } \\
& \mathrm{s}=\text { standard deviation } \\
& \mathrm{n}=\text { number of runs (e.g. } 40) \\
& t_{[1-\alpha / 2, v]}=t \text {-statistic for the given parameters (e.g. 2.021) }
\end{aligned}
$$


A summary of the project duration from each of the simulation runs is given in Table II. A summary of the $95 \%$ confidence interval for the mean process duration as predicted by CYCLONE and SLAM II is given in Table III.

\section{USING SIMULATION FOR DECISION MAKING}

After simulation models have been developed and validated, they can be used for testing and comparing different alternatives (Halpin et al. 1988). For example, schmitt (1990) used simulation to compare the different TEC methods in different soil conditions and

Table II. Project duration obtained from simulation runs

Deterministic

\begin{tabular}{||l|l||}
\hline SLAM II & CYCLONE \\
\hline 1,117 minutes & 1,117 minutes \\
\hline
\end{tabular}

Stochastic - Forty Experiments

\begin{tabular}{||l|l|l||}
\cline { 2 - 3 } \multicolumn{1}{c|}{} & SLAM II & CYCLONE \\
\hline Mean & 1,150 minutes & $1,144.45$ minutes \\
\hline Sample STD & 13.1 minutes & 17.552 minutes \\
\hline
\end{tabular}

Note: STD stands for standard deviation

Table III. 95\% confidence interval for the mean process duration

\begin{tabular}{||l|l|l||}
\cline { 2 - 3 } \multicolumn{1}{c|}{} & Lower Limit & Upper Limit \\
\hline SLAM II & $1,145.8$ minutes & $1,154.2$ minutes \\
\hline CYCLONE & $1,138.8$ minutes & $1,150.1$ minutes \\
\hline
\end{tabular}

for different diameter sizes of liner or casing. He obtained the mean project duration for different TEC methods used under different original conditions. This type of comparison is very valuable to the owner of the project, because a set of comparisons can be established in order to make a decision on the type of TEC method to use. other applications include modeling and simulating different equipment for the purpose of comparing their output, simulation of trenchless versus open cut to compare cost, time, and production, establishing production rates for use on bidding new projects, and in resolutions of claims and litigations. 


\section{CONCLUSIONS}

This paper has discussed how computer simulation can be used in assisting a project manager in making a decision regarding a technology to be used in a given situation. The uses of simulation in comparing alternative systems as well as other project management situations have also been highlighted. It was shown that CYCLONE with it four basic modeling element and the user friendly environment of MicroCYCLONE provided the same results as SLAM II, a leading general purpose simulation language. This shows that simulation is affordable from a learning perspective, can be easy to use with the proper choice of the simulation language, and provides great benefits in assisting a project manager in making a wise decision.

\section{REFERENCES}

1. Halpin, Daniel W. (1990). MicroCYCLONE user's manual. Division of Construction Engineering and Management, Purdue University, West Lafayette, Indiana, USA.

2. Halpin, D.W., AbouRizk, S.M., and Hijazi, A.M. (1989). "Sensitivity Analysis of Construction operations." Proceedings 7 th National Conference on Microcomputers in Civil Engineering, orlando, Florida, USA, November.

3. Lluch, José and Halpin, Daniel W. (1982). "Construction operations and microcomputers," Journal of the Construction Division, ASCE, Vol. 108, No. CO1, March 1982.

4. Iseley, David Thomas (1988). Automated methods for the trenchless placement of underground utility systems. Thesis presented in partial fulfillment of the requirements for the Degree of Doctor of Philosophy. School of Civil Engineering, Purdue University, West Lafayette, Indiana, USA.

5. Pritsker, A. Alan B. (1986). Introduction to simulation and SLAM II, Third Edition, A Halsted Press Book, John Wiley and Sons, New York.

6. Schmitt, Robert L. (1990). "simulation of trenchless excavation construction." Independent Research Project, Division of Construction Engineering and Management, Purdue University, West Lafayette, Indiana, USA.

7. Thomson, J. (1987). "Trenchless pipelaying applications and market," Proceedings NO-DIG 87, Second International Conference and Exhibition of Trenchless Construction for utilities, London, April. 


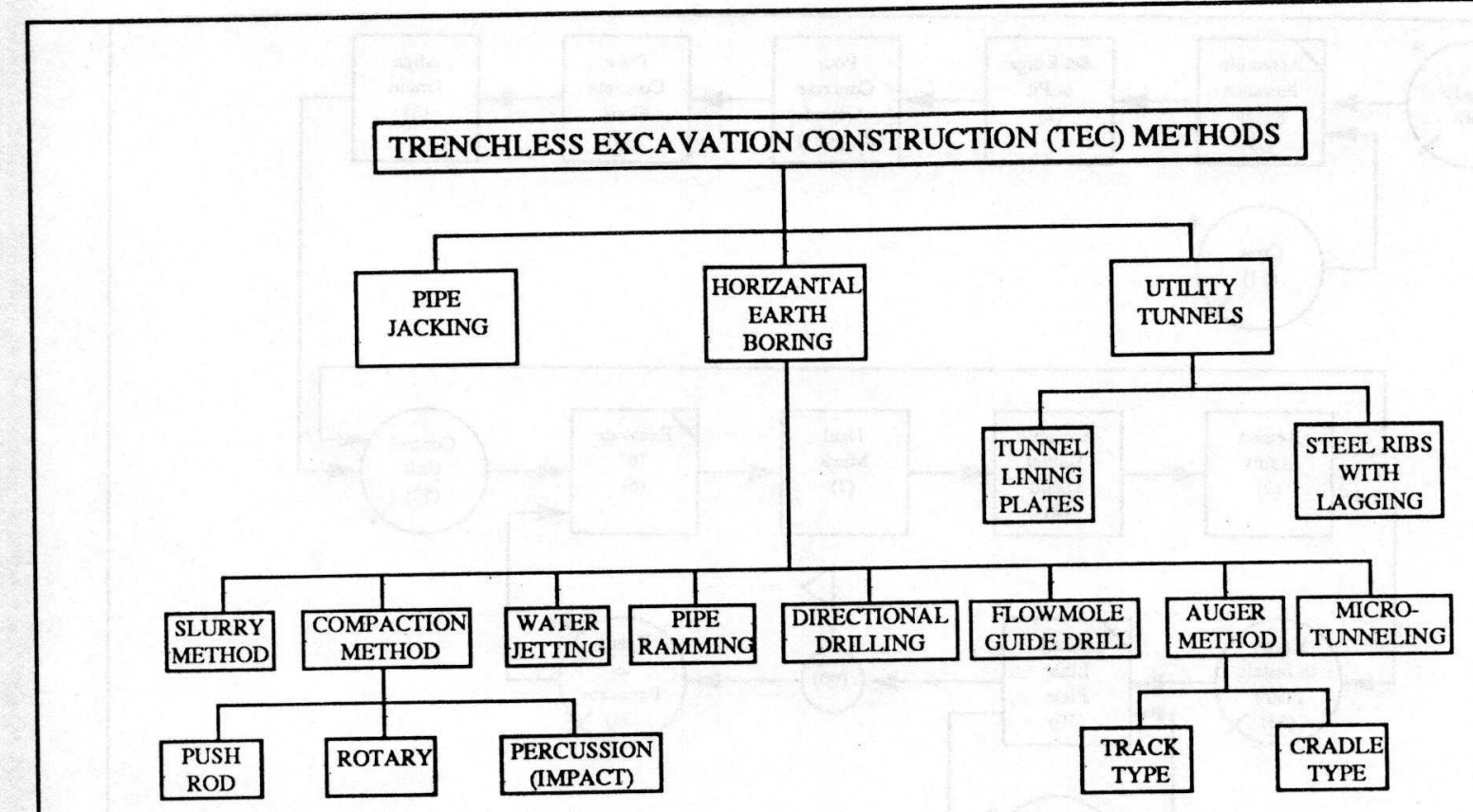

Figure 1. Trenchless excavation construction classification system (Iseley 1988)

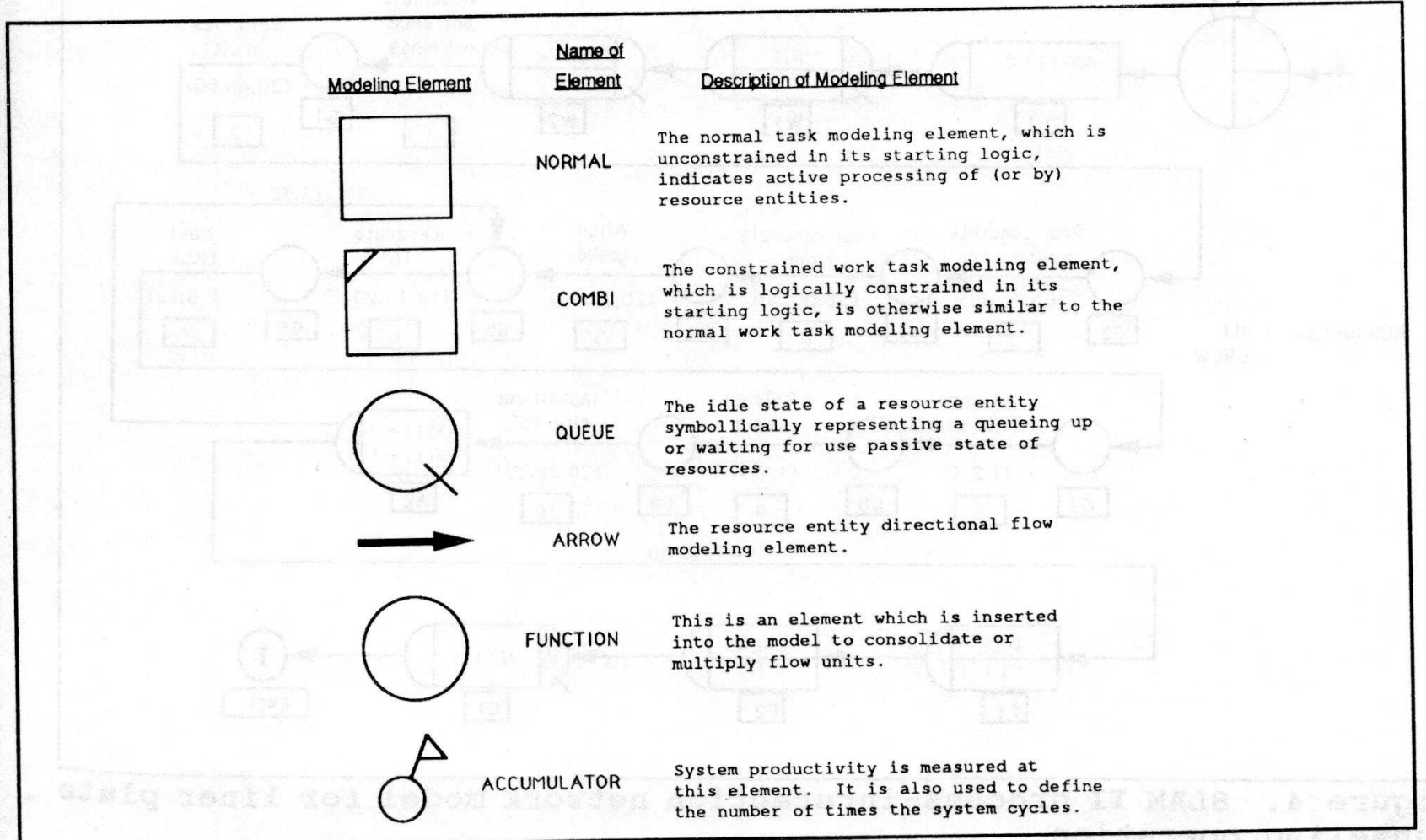




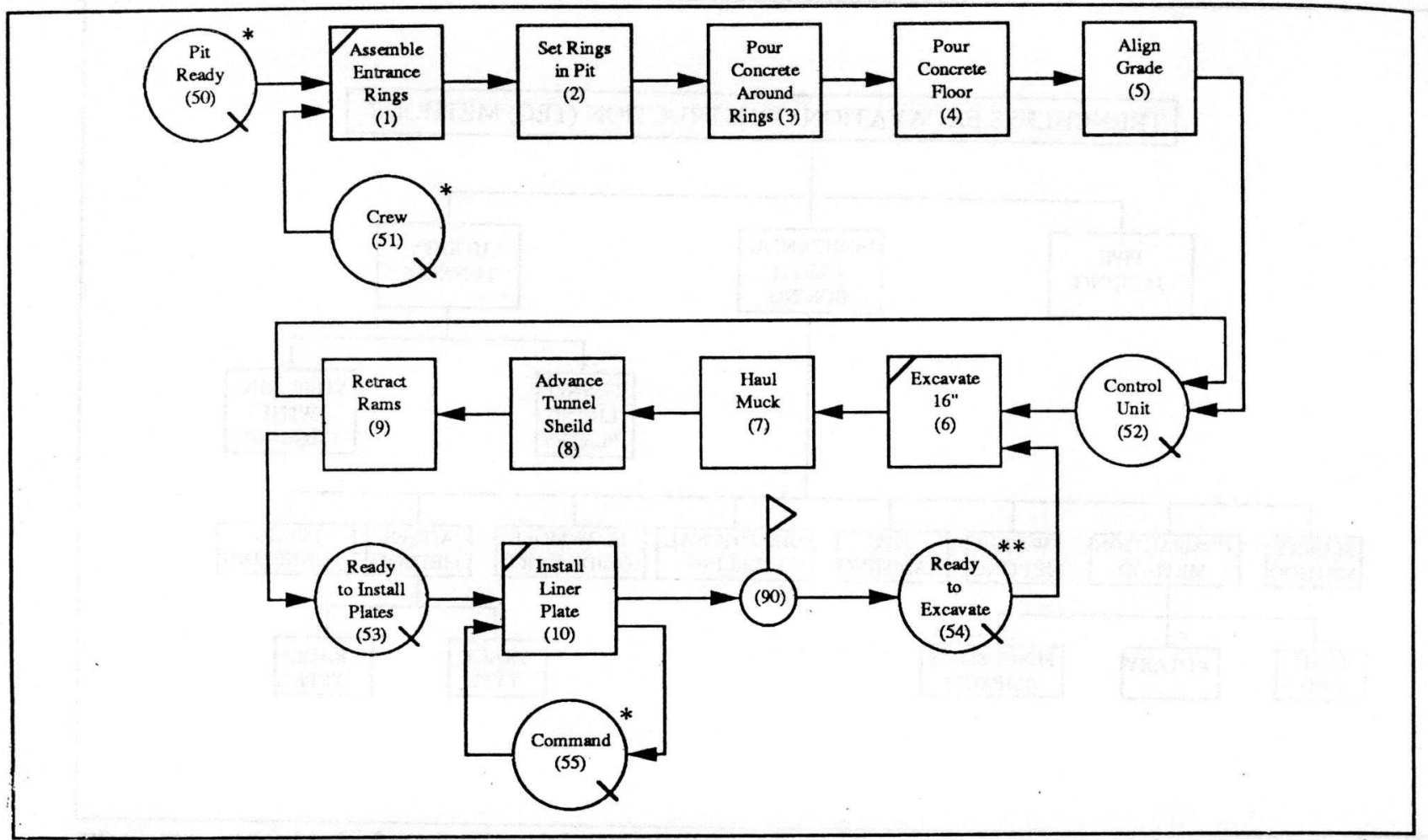

Fiqure 3. CYCLONE network model for liner plate tunneling operation (Scimitt 1990)

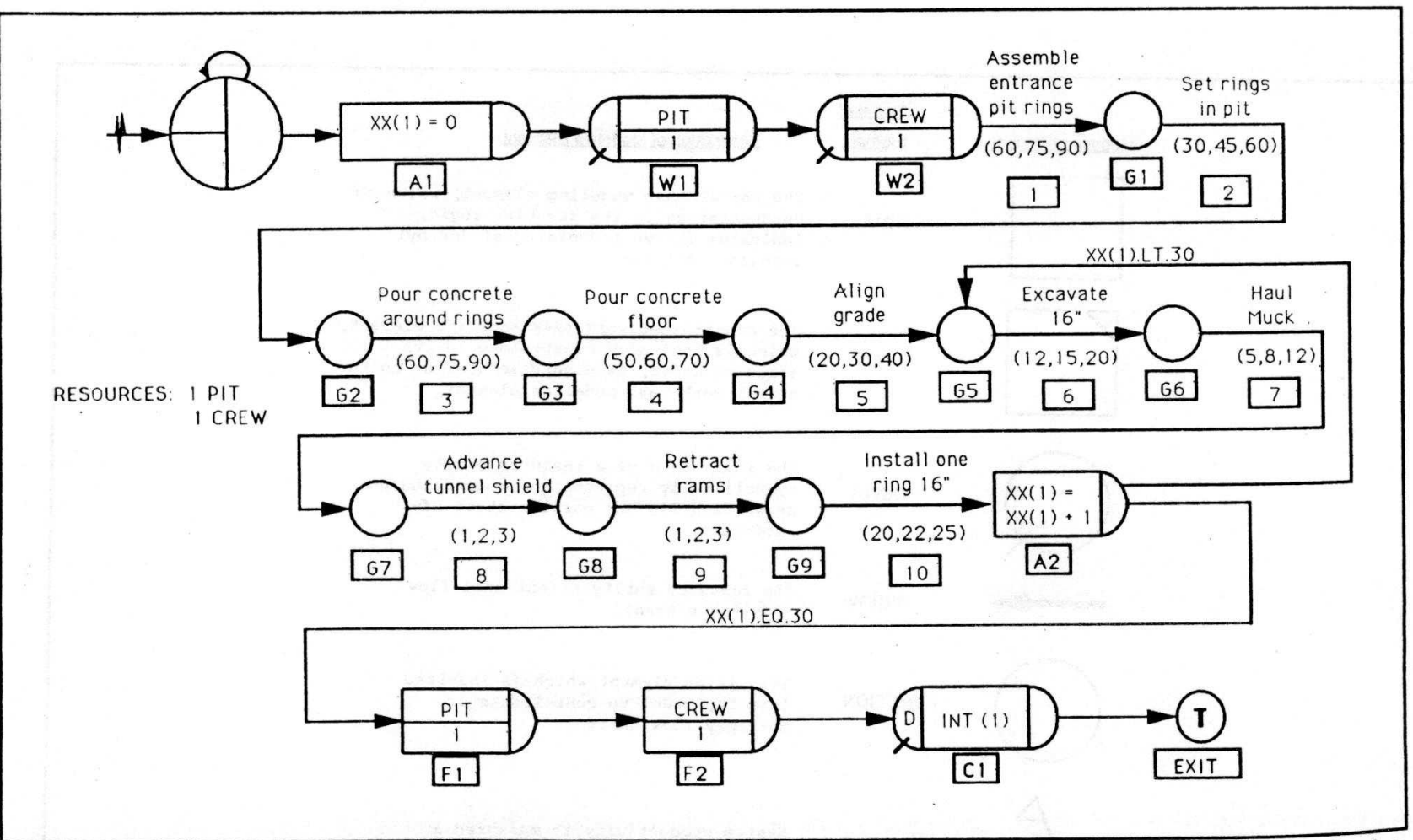

Figure 4. SLAM II process-interaction network model for liner plate tunneling operation 